\title{
Jorge Amado 2012 Jorge Amado 2012
}

\author{
Mia Couto*
}

RESUMO: A IMPORTÂNCIA DE JORGE AMADO PARA OS ESCRITORES E AS LITERATURAS DOS PAÍSES AFRICANOS DE LÍNGUA PORTUGUESA.

ABSTRACT:.THE IMPORTANCE OF JORGE AMADO FOR BOTH WRITERS AND THE LITERATURES OF PORTUGUESE-SPEAKING AFRICAN COUNTRIES.

PALAVRAS-CHAVE: JORGE AMADO; ÁFRICA; BRASIL; CULTURA; LITERATURA. KEYWORDS: JORGE AMADO; AFRICA; BRAZIL; CULTURE; LITERATURE.

* Escritor moçambicano. Associação dos Escritores Moçambicanos, Maputo, Província de Maputo, Moçambique. E-mail: impacto@impacto.co.mz. 
ois avisos prévios:

Um, primeiro - não venho falar sobre Jorge Amado. Não sou especialista em Jorge Amado e seria uma pretensão grave pensar que tenho competência para falar da literatura brasileira.

$\mathrm{O}$ que vou tentar trazer aqui é somente a ideia da importância que Jorge Amado teve para os escritores africanos de língua portuguesa, o que quer dizer os escritores de Angola, Moçambique, Cabo Verde, Guiné-Bissau e São Tomé e Príncipe. Devo dizer já, em nome da verdade, que Jorge Amado não me marcou exatamente como uma influência na construção da minha própria escrita. Sou mais colado a outros escritores e a outro tipo de escrita que nasceu e nasce neste país. Achei importante fazer esta declaração antes de entrar na porta.

De um modo antecipado e sumário, a verdade é a seguinte: Jorge Amado não foi apenas o mais lido dos escritores estrangeiros nos territórios africanos de língua portuguesa. Ele foi o escritor que maior influência teve na gênese da nossa literatura. A pergunta poderia ser: por que essa enorme e declarada influência? Este é o meu assunto, ciente de que não falarei apenas de um escritor, mas das viagens que a escrita nos autoriza.

Um segundo aviso prévio:

Eu não poderei deixar de fazer referência a um triângulo que é composto por três vértices: Jorge Amado, o Brasil e África. Cada um destes três pontos não pode ser visto senão no contexto de um triângulo em construção. Tratar cada um deles como se fosse uma realidade essencial é fruto de inúmeros equívocos. Primeiro, o próprio Jorge Amado. Ele é um autor de várias vozes e produziu uma obra de percursos e momentos profundamente variados. $\mathrm{O}$ segundo vértice seria África e aqui é preciso insistir no seguinte: África é o mais plural dos continentes. Nenhum outro possui tanta diversidade cultural, étnica e linguística. Esta afirmação de diversidade é algo muito comum na nossa fala mas ainda entrou pouco no nosso pensamento.

Procurar África dentro da obra de Jorge Amado pode ser objeto de algum equívoco. O perigo é tentar isolar aquilo que se identifica como "africano" por razão de um estereótipo ou de uma simplificação que acaba por negar a complexidade do continente de onde eu venho. À força de querermos ser parecidos com o Outro acabamos por anular a sua existência. O mesmo perigo existiria se tentássemos averiguar quanto de Europa ou quanto de árabe 
existe na obra de JA. Todas estas tentativas, por muito interessantes que sejam, caminham por um trilho arriscado que é purificar elementos essenciais numa realidade cuja beleza é exatamente escapar a estas simplificações. Eu mesmo sou, muitas vezes, consumidor e produtor destes clichês. Nesse breve texto usarei, aqui e ali, desses lugares comuns sobre África e sobre o Brasil. E é verdade que na Bahia eu me sinto mais em casa do que em qualquer outro ponto do Brasil. E uma grande parte da familiaridade resulta da composição racial desse lugar. Mas essa sensação de estar em casa resulta sobretudo da presença dominante de uma relação humana, de uma presença do tempo e de coisas inefáveis como o modo de ser dono do caminhar, o modo de falar com o corpo, o modo como as pessoas dormem sobre um muro como se, nos dois lados do Atlântico, o muro tivesse a intimidade de uma cama (estou usando uma expressão do Alberto Costa e Silva).

Diz-se que a grande maioria da população da Bahia é de origem africana. Mas eu diria que o Brasil todo é de origem africana. O Brasil não é apenas de origem africana como ele guarda uma África que, em larga medida, já não existe no próprio continente africano. Na verdade, a África que existe no Brasil é quase sempre uma criação brasileira. Mas também, no Brasil persistem enormes desconhecimentos e equívocos sobre África e os africanos.

Os condimentos africanos da cultura brasileira não podem ser olhados como heranças que se localizam apenas no passado. Estão sendo construídos, apagados e reconstruídos no presente. O que eu vejo é que alguns círculos brasileiros que se reclamam da África estão hoje pensando-se a si mesmos inspirados mais nos Estados Unidos da América do que no continente africano. Isso implica uma deslocação de uma religiosidade profundamente africana para uma outra mais puritana e mais europeia. Não há aqui nenhum juízo de valor, apenas uma simples constatação da mobilidade dos projetos identitários. Mas eu fico muito feliz com o fato de, nos últimos anos, se ter verificado uma maior proximidade e um conhecimento muito mais efetivo da nossa realidade africana. Fico feliz também porque essa maior proximidade revelou aos brasileiros uma África que é tão complexa e múltipla que não cabe num único nome.

Volto para o terreno da literatura. E começo por uma pequena história. Uma história verdadeira. No deambular do século dezenove, uma moçambicana chamada Juliana vivia no sossego da sua pequena Ilha junto ao oceano 
Índico. A pacatez de sua vida foi subitamente alterada numa tarde em que o seu pai, um próspero comerciante chamado Souza Mascarenhas, trouxe para casa um homem doente. O hóspede ardia em febre e, para garantir tratamento, Juliana foi a enfermeira de serviço, na lenta recuperação do intruso. $\mathrm{Na}$ convalescença, Juliana e o homem se apaixonaram. A ternura de Juliana era devolvida em versos rabiscados em folhas dispersas. Pouco tempo depois, os dois casaram e tiveram muitos filhos.

Isto que acabei de ler é, dirão vocês, enredo de novela. Ou letra de canção de uma dupla sertaneja. Neste caso, porém, este relato corresponde à realidade. O homem doente que pagava em versos era um brasileiro - chamado Tomás Antônio Gonzaga, o inconfidente mineiro desterrado. Intencionalmente fiz terminar esta historinha no clichê "casaram-se, tiveram muitos filhos e foram muito felizes" apenas para insistir numa evidência perigosa: parece que, em toda a narrativa universal, só há história desse momento em que começa a felicidade absoluta. Depois disso não há mais nada que valha a pena contar. Falo nesta tendência de acabar a história quando começa a felicidade, porque Jorge Amado trabalhou muito na transgressão desse limite. Ele teve o condão de ser um autor feliz, um autor solar (como chamou Mario Vargas Llosa). E falo disto porque esta habilidade em ser ocupado pela alegria, em produzir um presente já ocupado pelo futuro é possivelmente uma marca da religiosidade africana.

Parecia pois que não haveria mais a contar. No caso vertente, porém, do brasileiro Antônio Gonzaga e da moçambicana Juliana há qualquer coisa que desponta no enredo. Porque nos demorados serões da casa colonial se juntava a gente culta da Ilha de Moçambique e o brasileiro declamava poesia. Esses serões faziam nascer o primeiro núcleo de poetas e escritores na Ilha de Moçambique, a primeira capital da colônia de Moçambique.

Algo semelhante sucedia com Gregório de Matos, o exilado em Angola. Nesse outro lado, também o baiano ajudou na criação de núcleos intelectuais e literários. Contudo, é preciso dizer que, tanto num lado como no outro, esses níveis de influência direta foram restritos e muito pouco duradouros.

Por outro lado, as obras desses autores devem ser colocadas em contexto histórico. O Brasil que eles trazem consigo é um território carregado de Europa, uma outra colônia envergonhada da sua tropicalidade. Gonzaga casa com uma filha de traficante de escravos. E Gregório de Matos tem um olhar magoado sobre aquilo que ele chama de "sua Pátria", mas uma pátria que ele 
lamenta estar infeccionada pela mestiçagem, sendo a mestiçagem, para ele, uma condenação ao perpétuo atraso. Eis os seguintes versos que ele escreve ao sair do porto da Bahia:

Não sei por que fui nascer

neste Brasil empestado

Eu, um homem branco e honrado, sem outra raça.

Terra tão grosseira e crassa, que a ninguém se tem respeito, salvo a quem mostra algum jeito de ser mulato.

Tudo isto foi um passado de ocorrência anedótica e pontual. Um século depois, nascia na África uma corrente de intelectuais ocupados em confrontar a dominação colonial e procurar a sua própria identidade individual e coletiva. Nessa altura, era clara a necessidade de rupturas com os modelos europeus. Escritores de Angola, Moçambique, Cabo Verde, Guiné-Bissau e São Tomé e Príncipe procuravam caminhos para uma escrita mais ligada à sua terra e à sua gente. Carecíamos de uma escrita que nos tomasse como personagem, de uma narrativa que nos escrevesse a nós mesmos.

Nas décadas de cinquenta, sessenta e setenta, desembarcaram no outro lado do oceano vários autores: Manuel Bandeira, Mário de Andrade, Rachel de Queiroz, Lins do Rego, Erico Veríssimo, Drummond de Andrade, João Cabral de Melo Neto e tantos outros.

E desembarcou uma revista, O Cruzeiro, com personagem marcante como o Amigo da Onça, com o humor de Millôr Fernandes, as crônicas de Rachel de Queiroz.

O castigo de ir ao barbeiro era compensado pela oportunidade de fazer essa viagem por um mundo aberto à ironia e ao riso.

Mais do que todos, porém, desembarcou o baiano Jorge Amado. Os livros de Jorge cruzaram o Atlântico e causaram um impacto extraordinário no nosso imaginário coletivo.

Esse fascínio atingiu intensamente os círculos dos poetas e escritores do meu país. Em minha casa, meu pai - que era e é poeta - deu o nome de Jorge a um filho e de Amado a um outro. Apenas eu escapei dessa nomeação referencial. 
Recordo que, na minha família, a paixão brasileira se repartia entre Graciliano Ramos e Jorge Amado. Mas não havia disputa: Graciliano revelava o osso e a pedra da nação brasileira. Amado exaltava a sensualidade e a festa desse mesmo Brasil.

E voltamos à pergunta que norteia a minha intervenção: por que este absoluto fascínio por Jorge Amado, por que esta adesão imediata e duradoura?

É evidente que a primeira razão é literária, e reside inteiramente na qualidade do texto de escritor baiano. Um dos segredos do seu fascínio: a sua artificiosa naturalidade, a sua elaborada espontaneidade, a capacidade de construir enredos e personagens que o leitor jamais esquecerá.

Hoje, ao reler os seus livros, ressalta esse tom de conversa íntima, uma conversa à sombra de uma varanda que começa em Salvador da Bahia e se estende para além do Atlântico. Nesse narrar fluído e espreguiçado, Jorge vai desfiando prosa e os seus personagens saltam da página para a nossa vida cotidiana.

O escritor Gabriel Mariano, de Cabo Verde, escreveu o seguinte: "Para mim a descoberta de Amado foi um alumbramento porque eu lia os seus livros e estava a ver a minha terra. E quando encontrei o Quincas Berro d'Água eu estava a vê-lo na Ilha de São Vicente, na minha rua de Passá Sabe..."

Esta familiaridade existencial foi, certamente, um dos motivos do fascínio nos nossos países. Os seus personagens eram vizinhos não de um lugar, mas da nossa própria vida. Gente pobre, gente com os nossos nomes, gente com as nossas raças passeavam pelas páginas do autor brasileiro. Ali estavam os nossos malandros (contados por narrador que também era malandro), ali estavam os terreiros onde falamos com os deuses, ali estava o cheiro da nossa comida, ali estava a sensualidade e o perfume das nossas mulheres. No fundo, Jorge Amado nos fazia regressar a nós mesmos.

Em Angola, o poeta Mário António e o cantor Ruy Mingas compuseram uma canção que dizia:

\section{Quando li Jubiabá}

me acreditei Antônio Balduíno.

Meu Primo, que nunca o leu

ficou Zeca Camarão. 
E era esse o sentimento: Antônio Balduíno já morava em Maputo e em Luanda antes de viver como personagem literário. $\mathrm{O}$ mesmo sucedia com Vadinho, com Guma, com Pedro Bala, com Tieta, com Dona Flor e Gabriela e com tantos outros fantásticos personagens.

O poeta Maurício de Almeida Gomes escreve o seguinte, em 1958:

Ribeiro Couto e Manuel Bandeira, poetas do Brasil, do Brasil, nosso irmão,

disseram:

“-É preciso criar a poesia brasileira, de versos quentes, fortes, como o Brasil, sem macaquear a literatura lusíada."

O meu amigo angolano David Mestre fala de uma tertúlia que em Luanda se criou e se chamou "Leões da Anhara", que incluía Ernesto Lara Filho e outros grandes nomes da literatura angolana e tinha em Jorge Amado (na década de 60) uma referência primordial. O poeta David Mestre disse o seguinte: "viveu-se então intensamente, nestas paragens, a febre de Jorge Amado". Os pastores da noite serviu para aqueles boêmios de um verdadeiro livro de curso; A morte e a morte de Quincas Berro d'Água foi outra bíblia de boa vagabundagem. Mas sobretudo foi por razões literárias que o baiano fazia sucesso na tertúlia. Jorge não escrevia livros, ele escrevia um país. E não era apenas um autor que nos chegava. Era um Brasil todo inteiro que regressava à África. Havia pois uma outra nação, que era longínqua, mas não nos era exterior. E nós precisávamos desse Brasil como quem carece de um sonho que nunca antes soubéramos ter. Podia ser um Brasil tipificado e mistificado mas era um espaço mágico onde nos renascíamos criadores de histórias e produtores de felicidade.

Onde se criava mais esse efeito de espelho não era exatamente nas personagens e nos cenários: era na religiosidade, numa relação com o divino feito plural e próximo, na fluida fronteira entre os mortos e os vivos. Os negros, mulatos e brancos brasileiros eram-nos próximos porque os seus deuses falavam, cantavam e dançavam como as nossas divindades. 
Descobríamos essa nação num momento histórico em que nos faltava ser nação. O Brasil - tão cheio da África, tão cheio da nossa língua e da nossa religiosidade - nos entregava essa margem que nos faltava para sermos rio. Nós vivíamos sob um regime de ditadura colonial. As obras de Jorge Amado eram objeto de interdição. Livrarias foram fechadas e editores foram perseguidos por divulgarem essas obras. O encontro com o nosso irmão brasileiro surgia, pois, com épico sabor da afronta e da clandestinidade. A circunstância de partilharmos os mesmos subterrâneos da liberdade também contribuiu para a mística da escrita e do escritor. $\mathrm{O}$ angolano Luandino Vieira, que foi condenado a 14 anos de prisão no Campo de Concentração do Tarrafal, em 1964 fez passar para além das grades uma carta em que pedia o seguinte: "Enviem o meu manuscrito ao Jorge Amado para ver se ele consegue publicar lá, no Brasil..."

Luandino Vieira é talvez o mais importante escritor nosso, aquele que mais nos instigou a partir de dentro. Ele foi o único caso de um escritor que recusou o Prémio Camões. E foi ele quem me alertou da importância que teve para a sua própria escrita o encontro com Guimarães Rosa. Vale a pena escutar como Luandino considera hoje o papel do Brasil na construção da sua escrita. Eis o que ele disse recentemente numa entrevista a Joelma dos Santos, da Universidade de Pernambuco:

E a Literatura brasileira chegava-me por vias legais e por vias clandestinas: Lins do Rego, Rachel de Queiroz, Jorge Amado, Erico Veríssimo; os poemas de Manuel Bandeira, que nós descobrimos antes de Drummond, os poemas de Bandeira circulavam quase como panfletos, a gente fazia cópia e os distribuímos por entre perigos e ameaças. Essa influência não ocorreu de forma ampla, mas ela foi muito profunda.

Eu lembro que o primeiro livro que comprei, tinha dezesseis anos, eu saí de casa, fui trabalhar, e o primeiro dinheiro que eu ganhei, eu fui buscar, e comprei um livro de Erico Veríssimo; ainda tenho este livro, que diz: "comprado com o meu primeiro dinheiro". Esses livros fizeram de mim quem sou. Mas foi sobretudo Jorge Amado que me deu uma visão da humanidade, dos seus personagens, da inclusão de todo o tipo de personagem como tão valioso como qualquer outro tipo de personagem e, sobretudo, o modo como ele incluiu e dignificou o Negro na sua Literatura, isso ninguém pode mais esquecer. 
Um novo parênteses: nós vivemos hoje um tempo de democracia que é relativamente recente. Lembro amigos meus que, a exemplo do que sucedeu com Amado, tiveram que fugir do Brasil e uns foram parar a Moçambique.

É tão importante homenagear Amado como criador ficcionista como lutador pela liberdade. Não apenas lutou contra a opressão da ditadura mas foi capaz de romper contra aquilo que ele sentia ser asfixiante na pertença ao seu próprio partido. É preciso não esquecer que os seus livros que hoje aqui celebramos foram queimados pela ditadura exatamente em Salvador. É preciso celebrar a vida e generosidade de um ateu que foi autor do decreto que em 1946 criou a Lei da Liberdade de Culto religioso.

$\mathrm{Na}$ realidade, os poetas nacionalistas africanos ergueram Amado como uma bandeira. Há um poema da nossa mais importante poeta, Noémia de Sousa, que se chama "Poema de João", escrito em 1949, e que começa assim:

João era jovem como nós

João tinha os olhos despertos,

As mãos estendidas para a frente,

A cabeça projectada para amanhã,

João amava os livros que tinham alma e carne

João amava a poesia de Jorge Amado.

E há, ainda, uma outra razão que nós poderíamos chamar de ordem linguística.

No outro lado do mundo se revelava a possibilidade de um outro lado da nossa língua. E nada é mais íntimo que o idioma. Na altura, nós carecíamos de um português sem Portugal, de um idioma que, sendo do Outro, nos ajudasse a encontrar uma identidade própria. Até se dar o encontro com o português brasileiro, nós falávamos uma língua que não nos falava. E ter uma língua assim, apenas por metade, é um outro modo de viver calado. Jorge Amado e os brasileiros nos devolviam a fala, num outro português, mais açucarado, mais dançável, mais a jeito de ser nosso.

O poeta maior de Moçambique, José Craveirinha, disse o seguinte numa entrevista: 
Eu devia ter nascido no Brasil. Porque o Brasil teve uma influência tão grande que, em menino eu cheguei a jogar futebol com o Fausto, o Leonidas da Silva, o Pelé. Mas nós éramos obrigados a passar por João de Deus, um D. Dinis, pelos clássicos de Portugal. Numa dada altura, porém, nós nos libertámos com ajuda dos brasileiros. E toda a nossa literatura passou a ser um reflexo da Literatura Brasileira. Quando chegou o Jorge Amado, nós tínhamos chegado a nossa própria casa.

Foi isso que Jorge Amado nos deu. E foi isso que fez Amado ser nosso, africano, e nos fez, a nós, sermos também brasileiros. Essas travessias trocadas existiram na minha própria história.

Antes de desembarcar nos livros, o Brasil já me tinha chegado por vozes e cantos. Para mim chegou por via da voz rouca de um baiano chamado Dorival Caymmi. Eu tinha cinco anos de idade, e esse homem cantava e era como se uma saudade infinita me invadisse, uma saudade de um lugar onde nascera uma parte oculta de mim. Só daí podia vir essa estranha doçura de morrer no mar.

É doce morrer no mar (essa canção que Caymmi compôs com Jorge Amado e que fala ainda desse Mar morto que tinha sido publicado).

De qualquer modo, eu ficava na varanda escutando as canções de Caymmi, mas já embalado numa melancolia profunda que os meus pais achavam que não era coisa boa para a minha idade. Cuidando de me proteger, a minha mãe me conduziu à praia e, frente ao Oceano Índico, disse: “- Esse Dorival fala de morrer em ondas verdes. Vê, meu filho, vê se há ondas verdes."

As palavras de minha mãe me consolaram. Não por serem verdade mas por serem palavras de mãe. $\mathrm{Na}$ verdade, ela mesma sabia que não estava certa. Quem procura no mar ou na vida uma cor pura, uma essência de identidade, está navegando no equívoco. Quem quiser buscar para si mesmo uma identidade única (na forma de religião, de uma etnia ou de uma cultura) está na verdade tentando separar o sal da água. O mar da escrita de Jorge Amado não é aquele que banha a geografia. É o mar vivo das nossas vidas.

Autor convidado. 